\title{
2 \\ A NEW BUSINESS AS USUAL
}

\section{Introduction}

'Business as usual'-often shortened to the acronym BAU—is not always a bad thing, especially when it refers to proven, effective and productive business systems that help organisations achieve their aims. In recent times, however, BAU has received a bad rap and today is used more often as shorthand for institutions, programs, systems and ways of doing things that are ineffectual, and even dysfunctional.

BAU can also imply executive and organisational resistance to change, as well as a maladaptive attachment to legacy systems, protocols and operational policies. Doing things in a particular way 'because that is how they have always been done' is not a virtue, especially when business systems and processes act as an impediment to productive activity. That said, organisations sometimes demonstrate a maladaptive attachment to ineffective — and even anachronistic — ways of doing business. And those within organisations responsible for enforcing compliance with those systems sometimes play a gatekeeping role by discouraging alternative approaches (see Chapter 8, this volume).

Collaborative strategies are often pursued once it has been accepted that traditional programmatic approaches have failed and are sometimes portrayed as pathways to the creation of a new, or renewed, BAU. This implies a broad acceptance that pre-existing ways of doing business 
have not achieved the desired policy aims or delivered the expected social outcomes. It also implies a willingness to shake the tree and find new ways of working.

\section{An answer to complexity}

The logic of collaboration hinges on the recognition that no single organisation or sector acting on its own has the capacity or capability to solve complex policy problems. Complex, or wicked, problems occur in spaces where policy domains and formal accountabilities intersect. This is particularly true for each of the five cases investigated for this book.

Consider for a moment the policy domains in which our cases operate and the variety of agencies, not-for-profit organisations and professions that, in one way or another, play a role in meeting individual, family and community needs (Table 2.1).

Table 2.1 Policy domains and agencies of case studies

\begin{tabular}{|l|l|}
\hline Policy domain & Agencies and actors \\
\hline Vulnerable children & Police \\
Violence against & Courts \\
women and families & Individual/family/community support \\
& Housing \\
& Primary health care and hospitals \\
& Schools and early childcare services \\
& Drug and alcohol services \\
& Income support \\
& Women's and family refuges \\
& Mental health services \\
\hline Emergency services & Volunteer rural fire brigades \\
& State emergency services \\
& First responders (police, ambulance) \\
& Energy providers \\
& Telecommunications \\
& Community services and local community groups/organisations \\
& Schools and school authorities \\
& Local businesses and landowners \\
& Financial institutions \\
& Income support \\
& Hospitals \\
& Mental health providers \\
& Land management authorities (state forests, national parks, \\
& and so on) \\
\hline
\end{tabular}




\begin{tabular}{|l|l|}
\hline Policy domain & Agencies and actors \\
\hline $\begin{array}{l}\text { Reintegration } \\
\text { of offenders }\end{array}$ & Corrections and parole \\
& Housing providers \\
Individual/family/community support \\
Primary health care \\
Drug and alcohol support \\
Income support \\
Mental health support \\
Labour market support \\
\hline Childhood obesity & $\begin{array}{l}\text { Primary health and dental care } \\
\text { Community health care } \\
\text { Schools } \\
\text { Local councils } \\
\\
\text { Local retailers } \\
\text { Sporting organisations } \\
\text { Youth outreach } \\
\text { Health education }\end{array}$ \\
\hline
\end{tabular}

In each of these policy domains, achieving outcomes for individual clients, families and communities is highly dependent on different organisations, disciplines, public sector agencies, levels of government and community sector organisations working together-or, at least, not working against one another. No matter how much frontline workers want to have a positive impact on the lives of the people they serve, their natural tendency is to adhere to the formal policies and protocols prescribed by their employing organisations. Furthermore, because these same policies and protocols have also been designed to meet the needs of internal governance and assurance, they do not necessarily lend themselves to collaboration across organisational or sectoral lines.

\section{Barriers to changing BAU}

Institutional and systemic barriers to collaboration are, to some extent, hardwired into Australia's service delivery architectures. Repeated efforts to reform the bureaucratic, administrative state throughout the twentieth century largely focused on making government bureaucracy more effective and efficient in its operations (Forrer et al. 2014: 214-15).

New public management (NPM) was an earlier attempt to derive a new BAU. The reforms of the 1990s sought to remedy the inefficiency and inflexibility of state monopoly systems by encouraging creativity, flexibility and innovation in the delivery of public goods and services, introducing greater competition and becoming more customer-focused, decentralising authority, focusing on outcomes and fostering greater transparency and accountability for results (Forrer et al. 2014: 217). 
The older bureaucratic model of public sector leadership and management that had served well in providing standardised public services to large numbers of people proved itself unable to deal with the challenges presented by complex problems_-problems sharing the following characteristics:

- They are multijurisdictional, crossing local, state and even international borders.

- They are multi-programmatic, often involving several types of government programs and agencies.

- They do not lend themselves to command-and-control types of solutions.

- Citizens often interact indirectly with government; their chief contacts are with private or not-for-profit organisations.

- Leadership is diffused and must be coordinated to achieve best results.

- Although rules and procedures can provide a framework, the key to success is flexibility.

- Roles are determined by knowledge and ability, not by positional authority in a hierarchy (Forrer et al. 2014: 209-10).

These are precisely the kinds of problems that collaboration is intended to address. However, despite more than a decade of thinking about 'whole-of-government' or 'joined-up' approaches, collaboration across programmatic, organisational, portfolio and sectoral boundaries remains difficult and problematic (Carey et al. 2015).

\section{Countercultural, not counterintuitive}

There is a tendency for government and social-purpose organisations to employ the language of collaboration without demonstrating a commitment to making the cultural and operational adjustments required to collaborate. Clearly, collaboration is easier to talk about than it is to $d o$. The status quo endures, even when it no longer delivers results.

According to Canadian thought leader and associate of the Tamarack Institute Mark Cabaj, collaboration is not counterintuitive, but it is countercultural. ${ }^{1}$ Successful collaboration rests on a set of skills, behaviours and processes that represent a departure from accepted 'legacy' practices (Hanleybrown et al. 2014: 2) and often entails an agenda for

1 Mark Cabaj's presentation on cross-sector social impact networking was given in Canberra on 26 April 2018 and was co-sponsored by the Commonwealth departments of Social Services and Education and Training. 
change-change in the nature of relationships, networks, governance, accountability and ways of working. Leading and sustaining the kinds of change necessary for collaboration to occur are difficult, even when the logic of collaboration is broadly accepted.

\section{Collaboration as 'transgressive' practice}

The transgressive quality of collaboration derives from the fact that it usually involves the violation of accepted conventions, norms, rules and boundaries. Although some might think that describing collaboration as transgressive exaggerates the degree to which it violates organisational norms, many of the people interviewed for this study clearly perceive themselves to be working in ways that operate outside usually accepted bureaucratic conventions. Several interviewees invoked the aphorism 'collaboration is like designing and building an aeroplane while flying it'. They are operating in environments in which BAU no longer applies, boundaries are malleable, the limits of authority are untested, practical guidance is scarce and scrutiny is intense.

For the most part, collaboration occurs in a secondary operating space (see Chapter 6) in which many of the conventions of the primary operating space do not apply in quite the same way. Furthermore, the operational and behavioural norms that will apply in this secondary operating space are to a large extent undefined — at least at the outset—and need to be co-designed and coproduced by participants. For most participants, this means unlearning old norms and attitudes while creating and signing up to new ones. Moreover, these new norms might only apply within the collaboration space and thus require participants to become, effectively, 'bicultural' as they transition back and forth across a shifting boundary between the primary and secondary operating spaces.

Collaboration is also transgressive in the sense that participants (collaboration leads, in particular) often find themselves in the position of forcing operational or cultural change in the face of institutional or organisational resistance. The collaboration leads interviewed for our cases often speak about the need to judiciously test boundaries, to exercise (and then back up) their own judgement and to 'act first and seek forgiveness later'.

In this light, when people are asked to 'go forth and collaborate', they are, in effect, being asked to be disruptive, in the best sense of the word. Authorisers (ministers and executives) need to understand this; they need 
to be cognisant of the risk that attempts to encourage collaboration might generate pushback, territoriality and complaints-and they need to be prepared to provide executive cover for their collaboration leads. It is also incumbent on collaboration leads to keep their executive apprised of any potential repercussions and to provide them with timely briefings and assurances (see Chapter 6).

Collaboration is transgressive to the extent that it entails contradictions of and challenges to institutional rules, traditional practices, functional demarcations and programmatic systems. Sometimes described as 'creative rule-breaking', collaboration depends on a set of skills and aptitudes that do not entirely conform to those traditionally used in public sector recruitment (see Chapter 4).

For example, where public sector recruitment favours formal qualifications, functional skills and relevant work experience—all framed within particular institutional, organisational and programmatic settings-collaboration requires intellectual nimbleness, creativity, empathic communication, tenacity and a preparedness to 'work outside the square'. This might make collaboration a hard sell within Australia's public sectors, steeped as they are in hierarchical, rule-based and siloed cultures.

\section{Pushing organisational boundaries}

Collaboration is neither new nor an emerging theme in public policy and governance discourses. Even so, in terms of its framing and practice, collaboration is in reality often more 'aspirational' than 'actual'. Partnership-based approaches to public sector governance are based, ideally, on relational mechanisms such as trust, shared values, implicit standards, collaboration and consultation (as opposed to bureaucratic mechanisms based on control, hierarchy and chains of command) (Favoreu et al. 2016: 440). However, as Favoreu et al. (2016: 449) point out, the implementation of such approaches faces considerable obstacles in the form of 'cultural barriers and organisational routines that are difficult to overcome, such as partitioning, or the prevalence of the hierarchical logic, which tends to be contrary to the collaborative logic'. In the Australian context, Keast and Brown (2006: 51-52) observe that deliberative endeavours to forge more collaborative ways of working via network-based service delivery models can be jeopardised by failures to make adaptive changes to behaviours, expectations and processes. 
Moreover, this is a trans-Tasman phenomenon. In New Zealand, an expert panel established by the Minister for Social Development offered the following observations in relation to that country's approach to protecting vulnerable children:

Traditional delivery and purchase models have failed to provide a range of effective services and approaches or to be sufficiently childcentred. Stakeholders have described a siloed system with insufficient partnership and collaboration around children's needs. Current funding approaches are restrictive and do not permit innovation or the creation of sustainable services to meet changing needs.

The current system, with diffuse accountabilities across various agencies, has been ineffective in ensuring vulnerable children and families get the services they need, when and where they need them. A 'negotiation and best efforts' approach has failed, particularly with respect to government agencies. (Ministry of Social Development 2015: 64-65)

\section{Risk, disruption and innovation}

In a keynote address to a workshop on cross-sector working held at The Australian National University in 2015, a former Secretary of the Department of the Prime Minister and Cabinet, Peter Shergold, advocated new forms of governance to enable public sector agencies, not-for-profits and businesses to work collaboratively in the pursuit of agreed social aims.

Shergold (2016: 26) believes 'cross-sectoral working in the public interest could act to reinvigorate the participatory nature of democratic governance'. Forging new adaptive models for more collaborative governance would require a greater appetite on the part of policymakers for risk-taking within an authorising environment that embraces experimentation and accepts the possibility of failure. Addressing complex problems in public policy requires innovation, and innovation cannot occur in the absence of risk. Nor can government expect to pass all the risk on to nonstate actors-at least not if it wants to reap the rewards of risk-taking.

This appears to be well understood by another former head of the Department of the Prime Minister and Cabinet, Martin Parkinson, who in 2016 told the Committee for the Economic Development of Australia: 
Innovation is not certain to be successful. It often involves failure, sometimes a lot of it-innovation is, after all, inherently risky. Yet often we impose too many costs on the efforts of those who fail. (Martin 2016)

He went on to say that the public sector has to become more innovative, adding:

It's got to be okay to fail. If the incentive structure, whether in the private sector or in the public sector, doesn't allow you to fail and fail fast, and then if you've learned something, try and try again, then I think you actually might find it really hard to foster that culture of innovation that we all want to see. (Martin 2016)

Sørensen and Torfing (2012: 2) point out that many public organisations offer a stable operational platform for the exploration and exploitation of new ideas and solutions. The sheer size of the public sector enables it to absorb the costs of innovation failures, especially if they fail 'fast and cheap' (Sørensen and Torfing 2012: 2). Sørensen and Torfing (2012: 5) also observe that innovation in the public sector is enhanced by multiactor collaboration in that it 'draws upon and brings into play all relevant innovation assets in terms of knowledge, imagination, creativity, courage, resources, transformative capacities and political authority'-something market competition and bureaucratic steering fail to do.

Both innovation and collaboration can be stifled in the embrace of a rules-bound governance framework. If collaborative, adaptive and iterative approaches to policy formulation and delivery are to become second nature in both the public and the not-for-profit sectors, it will be necessary to surmount the obstacles posed by 'the organisational hand-brake of path-dependent legacies in government, business, and the not-for-profit sector' (Butcher 2015: 253).

Collaboration can provide the intellectual stimulus and incentives for risk-sharing required for finding new solutions to emerging problems.

\section{Instilling a collaborative mindset}

Over the coming decade, the public sector will need to be increasingly focused on outcomes, less siloed and portfolio-driven, and more reliant on collaboration, cooperation and co-design (Eccles 2016). Instilling a collaboration mindset, however, requires public sector agencies in 
particular to swim against the current of a system that incentivises rigid top-down steering and public sector silos in favour of interconnected networks of actors (Aagaard 2012: 4-5).

Collaboration has both formal and informal dimensions. Collaboration often occurs 'under the radar', engaged in by public entrepreneurs with a deep sense of public service, acting without executive mandate and following nonstandard procedures (O’Leary 2014: 17).

Actors in any sector might elect to collaborate informally with colleagues in other business units, organisations or sectors as part of their normal modus operandi for problem-solving. In so doing, they might be working within accepted, but undocumented, terms of engagement with the implicit sanction of their employing organisation. Alternatively, they might simply be operating within the dictates of their own sense of professional propriety and might not perceive any need to obtain formal sanction. Others, however, might choose not to engage in collaborative behaviours in the absence of an explicit directive or sanction.

In a case study of the Danish Crime Prevention Council, Aagaard (2012: 10-11) observed that, despite concerted attempts to establish a coordinated multi-stakeholder approach to crime prevention, participants in the collaboration remained 'primarily embedded in the institutional universe of their own organisation, and do not see themselves in any significant interdependent relation to other members'-in part because 'members are uncertain of what sort of backing they have from their own organisations in concrete matters'. Aagaard (2012: 14) concludes that 'there is still a lot of path dependency in the public sector' and further observes that path dependency serves to constrain and slow innovation.

Rosemary O'Leary (2014: 54) concludes that public sector managers would benefit from training aimed at instilling a 'collaborative mindset', encompassing:

- personal attributes (being open-minded, patient, change-oriented, flexible, unselfish, persistent, diplomatic, honest, trustworthy, respectful, empathetic, goal-oriented, decisive, friendly and having a sense of humour)

- interpersonal skills (such as good communication, the ability to listen and to work with people) 
- group process skills (including facilitation, interest-based negotiation, collaborative problem-solving, skill in understanding group dynamics, culture and personalities, compromise, conflict resolution and mediation).

O'Leary (2014: 55) offers the following recommendations to agency heads wishing to create a more collaborative environment:

- Accept ideas from people and places you would never think of.

- Learn from others.

- Bring in thought leaders who might create a spark of an idea in your employees.

- Seek people with strong public service motivation, dedicated to the overall wellbeing of citizens.

- Seek people who will think widely about options.

- Seek people willing 'to play outside their comfort zone'.

- Seek people comfortable with acting 'transformationally' rather than staying in an old 'transactional' mode.

- Seek people who can see collaborative advantage.

- Seek people with exemplary collaborative skills such as negotiation, conflict resolution, collaborative problem-solving, facilitation and strategy. If your employees do not have these skills, obtain training for them.

- Provide an enabling environment to buffer short-term factors that undermine the collaborative impulse.

- Empower network members to enable participation.

- Frame problems and solutions to create the space needed for collaborators to find productive ways to work together.

- Educate employees about the importance of the strategic use of individual attributes, interpersonal skills and group process skills while collaborating.

- Incentivise and reward collaboration among individuals and organisations.

- Embed collaboration in performance evaluation and core competencies.

- Document and share how collaborations are working so managers can learn from successful and failed experiences. 
- Reshape management and leadership education to include intensive self-assessment and emotional intelligence development.

- Address challenges to data sharing and incompatible technologies that block interagency and intra-agency collaborative work.

- Address structural barriers to interagency work.

In common with the majority of thought leaders in the 'collaboration space', Forrer et al. (2014) assert that leading organisations in crosssector collaboration requires a fundamentally different skill set to that required by the traditional bureaucratic model of public administration. They contend that cross-sector collaborations require leaders with the ability to forge common purpose among actors who have their own organisational agendas. Also critical is the ability to see the larger system beyond their own organisational niche because collaboration allows a variety of viewpoints and approaches to solving a particular public problem. Forrer et al. (2014: 234) suggest that four general areas of leadership are the most critical when addressing complex problems in a cross-sector environment:

1. Generating support from other actors.

2. Leading outside of one's formal role.

3. Understanding the wider system.

4. Building trust.

Of course, trust plays an essential role in the success of all collaborative endeavours, much more so than would be the case with a traditional program run by a single public agency or not-for-profit organisation (Forrer et al. 2014: 229).

\section{What the cases tell us}

Collaboration is posited as a remedy for the jurisdictional, organisational, programmatic and sectoral siloing that create and reinforce the fragmentation of service delivery. And for these reasons, collaborative approaches are most often applied to problems that are longstanding and have already proved resistant to attempts at resolution. 
Thus, in a real sense, the task of remedying the ineffectiveness of existing interventions becomes an important focus of collaboration. As one of our interviewees from New Zealand said:

We didn't need to be told it wasn't working; we'd known for many years it wasn't working. I worked with a workforce that worked their fingers to the bone and it still wasn't working. So, the desperation to give effect to things that were more effective for whänau [families] — that had to change. (Children's Action Plan)

Collaborations can also coalesce around informal initiatives or 'pilots' that have achieved local salience or prominence. That said, it is also clear from our interviews that there is a palpable weariness with pilot schemes, which tend to be time-limited, have finite resourcing, are tightly bounded in operational terms and are unable to gain traction or demonstrate sustainability.

The need for a new BAU was a consistent organising theme across each of our cases. Implicit in the call for a new BAU is the fact that pre-existing arrangements - often based on programmatic funding, highly specified contracts and multiple eligibility requirements, triage systems and authorising environments - are not working. In each of our five case studies, the push towards collaboration was fuelled by frustration with a status quo that:

1. constrained the ability of organisations and workers to efficiently and effectively mobilise resources and assets to respond to complex problems

2. created bureaucratic, operational and organisational barriers for individuals, families and communities seeking assistance with complex problems.

However, while people might regard the existing modus operandi as problematic, changing established practices and expectations is far from easy, as attested by one New Zealand interviewee:

I think everyone's first response is, 'This is asking more of me. I'm required to do more. I'm required to do what I already have to do in my paid job, and you're asking more of me now.' So, the change strategy has got to be about how you redefine BAU more so that it's actually BAU; this is the new way of working. That is, if you adopt this model you don't need to do the BAU any more; you're actually doing a new BAU. That's the hardest thing for people to get their heads around and understand. (Children's Action Plan) 
Another interviewee pointed out the tendency to resolve the perceived inconsistencies between the status quo and proposed new ways of working by resorting to 'compartmentalisation':

They are still maintaining a separation, I think, in terms of the perspective where people think: 'This is children's teamwork and then this is my BAU. As an agency, we give this much time to Children's Team and this much time to business as usual.' And we're saying: 'But actually all your resources should be working collaboratively, sharing information and coming up with one plan.' But they compartmentalise the work, so that perpetuates a kind of 'it's different to what we normally do', whereas we are saying: 'Actually, it is what you do.' (Children's Action Plan)

Collaborative approaches are sometimes represented as 'transformational'; however, any such claims must be treated carefully and likely fall into the realm of wishful thinking. Indeed, many of the people interviewed for this study have made such claims. Others, however, have offered a contrary view, suggesting that the impact of collaborative approaches on the dominant operating culture of organisations is slight and brief.

Also, collaborative approaches can sometimes meet internal resistance within partner agencies, especially when the practices and behaviours required for collaboration are perceived as transgressing operational rules and protocols or threatening organisational or personal authority and influence. In part, internal resistance to collaboration derives from scepticism or apprehension about the impact of collaboration: 'What if it fails?'

\section{Final observations}

The collaboration literature gives a lot of attention to the need to devise and navigate new ways of working-to overturn BAU and establish a new normal. However, collaboration is built on an implicit assumption that the environment is complex and dynamic and, therefore, in a state of continual flux. The informal or semiformal nature of collaboration suggests impermanence. Although collaborative approaches should aim to reframe BAU, there is a risk that the new ways of working will become rigid and codified and just as maladaptive as the ones they replaced. 


\section{Practice considerations}

1. Is there a collaborative mindset in your organisation? Does collaboration figure as an organising theme of your organisation's way of working, and does collaboration occur in practice?

2. Are people within your organisation free to engage collaboratively across programmatic, organisational or sectoral boundaries?

3. What opportunities exist in your organisation for employees to add to their collaboration skill set?

4. Does your organisation have any collaboration 'protocols' to guide and regulate collaborative processes?

5. What aspects of your organisation's/sector's BAU potentially acts to constrain or inhibit collaboration?

6. What would have to happen to allow for change to occur?

7. Is it presently possible in your organisation for people to 'lead from below'to exercise creativity and initiative in ways that are conducive to the revision of current practices or the adoption of new ones?

8. Are there people who occupy positions of influence within your organisation who might be prepared to champion or lead a process involving the review of, and reflection on, those aspects of BAU that are not conducive to collaboration?

9. Can you identify people in your organisation, or in your partner organisations, who might be enlisted as 'collaboration champions'?

\section{References}

Aagaard, P. 2012. 'Drivers and barriers of public innovation in crime prevention.' The Innovation Journal 17(1): 2-17.

Butcher, John R. 2015. 'Squaring the virtuous circle: Exploring the potential of the "five Cs".' Australian Journal of Public Administration 74(2): 249-56. doi.org/10.1111/1467-8500.12121.

Carey, Gemma, Pauline McLoughlin, and Brad Crammond. 2015. 'Implementing joined-up government: Lessons from the Australian social inclusion agenda.' Australian Journal of Public Administration 74(2): 176-86. doi.org/10.1111/ 1467-8500.12096.

Eccles, Chris. 2016. 'Chris Eccles: What will the public sector look like in ten years?' The Mandarin, 30 June. 
Favoreu, Christophe, David Carassus, and Christophe Maurel. 2016. 'Strategic management in the public sector: A rational, political or collaborative approach?' International Review of Administrative Sciences 82(3): 435-53. doi.org/10.1177/0020852315578410.

Forrer, John, James Jed Kee, and Eric Boyer. 2014. Governing Cross-Sector Collaboration. Bryson Series in Public and Nonprofit Management. Hoboken, NJ: John Wiley \& Sons.

Hanleybrown, Fay, John Kania, and Jennifer Splansky Juster. 2014. 'Essential mindset shifts for collective impact.' Stanford Social Innovation Review 12(4).

Keast, Robyn, and Kerry Brown. 2006. 'Adjusting to new ways of working: Experiments with service delivery in the public sector.' Australian Journal of Public Administration 65(4): 41-53. doi.org/10.1111/j.1467-8500.2006. 00503a.x.

Martin, Peter. 2016. 'Martin Parkinson tells CEDA Australian managers below par.' Sydney Morning Herald, 10 October.

Ministry of Social Development. 2015. Investing in New Zealand's Children and their Families: Expert panel final report. Wellington: New Zealand Ministry of Social Development.

O'Leary, Rosemary. 2014. Collaborative Governance in New Zealand: Important choices ahead. Wellington: Fulbright New Zealand.

Shergold, Peter. 2016. 'Three sectors, one public purpose.' In The Three Sector Solution: Delivering public policy in collaboration with not-for-profits and business, eds John Butcher and David Gilchrist, pp. 23-34. Canberra: ANU Press. doi.org/10.22459/TSS.07.2016.02.

Sørensen, Eva, and Jacob Torfing. 2012. 'Introduction: Collaborative innovation in the public sector.' Innovation Journal 17(1): 1-14. 
This text is taken from Collaboration for Impact: Lessons from the Field, by John Butcher and David Gilchrist, published 2020 by ANU Press, The Australian National University, Canberra, Australia.

doi.org/10.22459/CFI.2020.02 